\title{
Aeromechanics of Processes in the Flow Part of a Centrifugal Mill
}

\author{
Ostashko Ihor Oleksandrovych ${ }^{1, *}$, Vynohradov Borys Volodymyrovych ${ }^{1}$
}

1 Faculty of Mechanical, Ukrainian State University of Chemical Technology, Gagarin 8 Street, 49005, Dnipro, Ukraine

\begin{abstract}
The article deals with aeromechanical processes in a centrifugal mill operated at different rotational speeds. The trajectories of flows, the velocity and pressure fields have been investigated. The influence of various factors on the classification effectiveness and maximum diameters of the particles discharged from the grinding chamber has been revealed.
\end{abstract}

Keywords: Aeromechanic, centrifugal mill, flow, Navier-Stokes equations.

\section{Introduction}

Centrifugal mills are being widely used for grinding non-abrasive materials. These mills, despite different descriptions (centrifugal mills, centrifugal-impact mills, dismembrators, rotary-vortex mills, etc.) have one common feature, i.e. a working body that transmits kinetic energy to the material to be ground. The design of the working body and the method of the final class discharge are the major differences in these mills. The throughput of a centrifugal mill is estimated by the specific power consumption for grinding the material of a given class. The researchers of the Ukrainian State University of Chemical Technology have developed a centrifugal mill with a working body that minimizes the specific power consumption in the material grinding and enables the primary classification of the material [1-4].

The rotation of the working body generates air flows in the grinding chamber of a centrifugal mill. The patterns of discharge of the final fraction and the interactions of the ground material particles with the working body, chamber walls and each other are determined by the aeromechanics of the air flows. Therefore, a relevant issue was studying the aeromechanical processes in the grinding chamber during the material grinding and mechanisms for classifying and discharging the final product class from the centrifugal mill.

Given the presence of the high-speed moving units, material to be ground and turbulent flows in the grinding chamber, the research could only be carried out through the computer-aided mathematical modeling and finite element methods. The purpose of the study was to investigate the aeromechanics of flows in the grinding chamber of a centrifugal mill, taking into account the design features of its flow part and working body, parameters of the material to be ground, and inlet and outlet pressures; to identify the patterns of the influence of the above factors on the discharge of maximum diameters of the material being ground.

A large number of recent publications deal with numerical simulation of aeromechanical processes in centrifugal machines. Numerical solution of the aeromechanical processes was based on the non-stationary Navier-Stokes equations, continuity equation for the flow, and the turbulence model. This system of equations can be solved analytically only for a limited number of simplified problems.

Today, for numerical solution of the Navier-Stokes equations, several dozens 
of various schemes are used. Most of them have been developed for the system of equations in vortex-current function variables [5]. The general disadvantage of this approach is that it necessitates using, in one form or another, the boundary condition for vortex on a solid surface, such as the Thom condition, which serves as a condition of the first order of accuracy for mesh resolution. Moreover, the use of vortex-current function variables excludes the possibility of generalizing this method to spatial and turbulent flows. This explains an increased interest of researchers in solving the Navier-Stokes equations in the physical variables of velocity - pressure. This approach allows using a single algorithm for solving both two-dimensional and three-dimensional problems. However, this approach is associated with the difficulty calculating the pressure field as coordinated with the velocity field. In spite of the difficulties, this technique may be the most appropriate, provided that a sufficient power computer is available, high mesh resolution is entered, and the integration time is increased until the moment of obtaining acceptable convergence. Therefore, this approach was taken as the basis in the study.

In the up-to-date software-oriented packages for numerical solution of systems of differential equations, the initial stage of simulation is the creation of a 3-D geometric model that fully represents the geometry of the investigated volume of the flow part and the related components of a centrifugal mill.

\section{Experimental Section}

The design elements of the centrifugal mill, which form the geometry of the flow part, are shown in Figure 1: the pile shaft 1, the working body 2 , the grinding chamber 3 , the disk between the grinding and discharge chambers 4, the discharge fan 5 and the outlet pipe 6 .

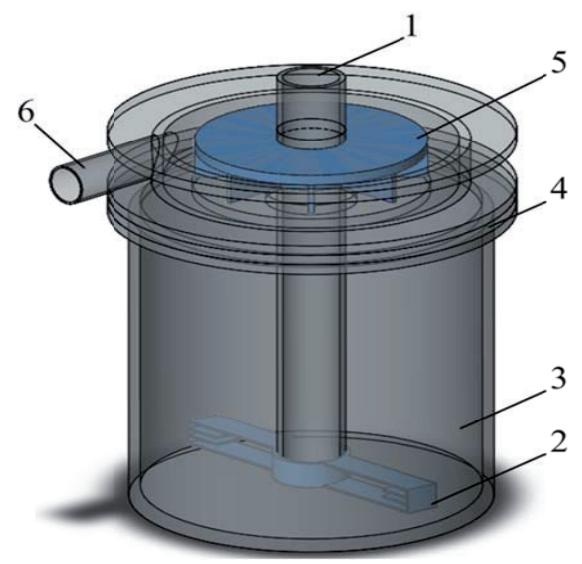

Fig. 1: Geometric model of the grinding chamber of a centrifugal mill.

The geometric model accurately represents not only the dimensions and geometry of the centrifugal mill units, but also their exact location in space relative to each other.

The aeromechanical processes in the centrifugal mill are described by the non-stationary NavierStokes equations and, in addition, by two k-w equations of the turbulence model, which were solved by the finite element method. The system of equations to be solved is presented below (1)

$$
\left\{\begin{array}{l}
\frac{\partial \bar{\rho}}{\partial t}+\nabla \cdot(\bar{\rho} \tilde{v})=0 ; \\
\frac{\partial(\bar{\rho} \tilde{v})}{\partial t}+(\bar{\rho} \tilde{v} \cdot \nabla) \tilde{v}=-\nabla \bar{p}+\nabla \cdot \bar{\tau}_{e f f} ; \\
\frac{\partial(\bar{\rho} k)}{\partial t}+\nabla \cdot(\bar{\rho} k \tilde{v})=\nabla \cdot\left[\left(\mu+\frac{\mu_{t}}{\sigma_{k}}\right) \nabla k\right]+\tilde{G}_{k}-Y_{k}+S_{k} ; \\
\frac{\partial(\bar{\rho} w)}{\partial t}+\nabla \cdot(\bar{\rho} w \tilde{v})=\nabla \cdot\left[\left(\mu+\frac{\mu_{t}}{\sigma_{w}}\right) \nabla w\right]+\tilde{G}_{w}-Y_{w}+D_{w}+S_{w} ; \\
\frac{\partial(\bar{\rho} \tilde{E})}{\partial t}+\nabla \cdot \tilde{v}(\bar{\rho} \tilde{E}+\bar{p})=\nabla \cdot\left[\left(\lambda+\frac{c_{p} \mu_{t}}{\operatorname{Pr}_{t}}\right) \nabla \tilde{T}\right]+\nabla \tilde{v}: \bar{\tau}_{e f f}+q_{v},
\end{array}\right.
$$

where: $\rho$ - is the density averaged over Reynolds, $\mathrm{kg} / \mathrm{m}^{3} ; t$ - hour, $\mathrm{s} ; \nabla-$ is the Hamiltonian operator, $\mathrm{m}^{-1} ; \tilde{V}$ - velocity vector, averaged over Favre, $\mathrm{m} / \mathrm{s}$; $p$ - pressure averaged over Reynolds, $\mathrm{Pa} ; k$ turbulent kinetic energy, J/kg; $\omega$ - relative velocity of dissipation of the kinetic energy of turbulence, $\mathrm{C}^{-1}$; $\mu$ - is the dynamic viscosity, Pa.s; $\mu_{t}$ - turbulent viscosity, Pa.s; $\sigma_{k}-\mu$ t weakening coefficient for small Reynolds numbers; $\tilde{G}_{k}$ - source member for $k$, $\mathrm{W} / \mathrm{m}^{3} ; \tilde{G}_{w}$ - source member for $\omega, \mathrm{kg} /\left(\mathrm{m}^{3} \cdot \mathrm{c}^{2}\right) ; S$ 
- strain rate tensor, $\mathrm{C}^{-1} ; D_{w}$ - a member taking into account cross-diffusion, $\mathrm{kg} /\left(\mathrm{M}^{3} \cdot \mathrm{c}^{2}\right) ; \tilde{E}$ - total mass energy, $\mathrm{J} / \mathrm{kg} ; \bar{\tau}_{\text {eff }}-$ deviator stress tensor, $\mathrm{Pa} ; q_{v}$ density of a volumetric source of heat, $\mathrm{W} / \mathrm{m}^{3} ; \tilde{T}-$ absolute temperature, averaged over Favre, $\mathrm{K}$.

The initial, boundary and conditions for (1) have the form:

$$
\begin{aligned}
& \left\{\begin{array} { l } 
{ \tilde { v } ( X ) = 0 ; } \\
{ \overline { p } ( X ) = p _ { 0 } ; } \\
{ k ( X ) = k _ { 0 } ; } \\
{ \omega ( X ) = \omega _ { 0 } ; } \\
{ \tilde { T } ( X ) = \tilde { T } _ { 0 } , }
\end{array} \quad \left\{\begin{array}{l}
n \cdot \tilde{v}=0 ; \\
\bar{p}=p_{\text {вих }} ; \\
k=k_{\text {вих }} ; \\
\omega=\omega_{\text {вux }} ; \\
\tilde{T}=\tilde{T}_{\text {вux }},
\end{array}\right.\right. \\
& \left\{\begin{array} { l } 
{ n \cdot \tilde { v } = \tilde { v } _ { B x } ; } \\
{ \overline { p } = p _ { B x } ; } \\
{ k = k _ { B x } ; } \\
{ \omega = \omega _ { B x } ; } \\
{ \tilde { T } = \tilde { T } _ { B x } , }
\end{array} \quad \left\{\begin{array}{l}
\tilde{v}=0 ; \\
n \cdot \nabla \bar{p}=0 ; \\
k=0 ; \\
\omega=\omega_{c m i} ; \\
n \cdot \nabla \tilde{T}=0,
\end{array}\right.\right.
\end{aligned}
$$

The computation was carried out in the Cartesian coordinate system using the international system of units Sl; the medium was real gas (air), the surface of solids was represented by an adiabatic wall with a roughness of $0 \mu \mathrm{m}$, the gravitational force was taken into account. The computational cells were of polyhedron type. The convergence of the computation results was assessed automatically by the convergence of the target, which was the absolute pressure and full velocity.

The equation was solved by the finite element method; the computational mesh consisted of 120433 cells in the flow part.

To verify the adequacy of the model and the reliability of the simulation results, these were compared with the experimental data.

\section{Results and Discussion}

At the initial stage of the simulation, the process aeromechanics in the flow part was studied with no material fed. Figure 2 shows the calculated results and the experimentally recorded air velocities at the outlet of the centrifugal mill grinding chamber at various rotor rotational speeds.

The above graphs illustrate that the discordance between the experimental and calculated data does not exceed $7 \%$, which confirms the adequacy of the developed model.

The results of the mathematical modeling of the

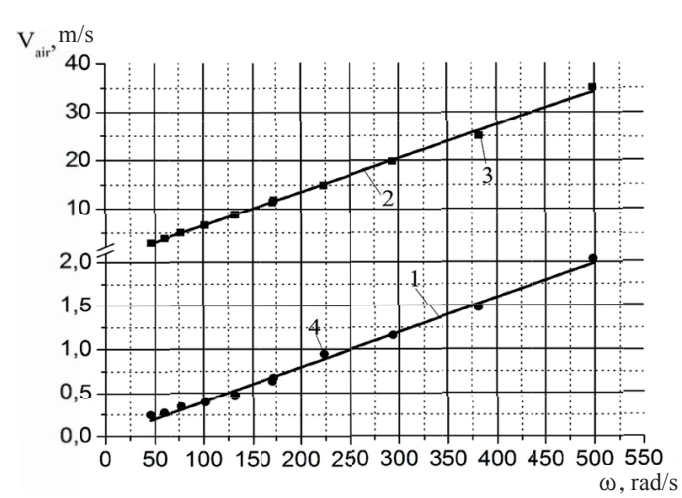

Fig. 2: Dependence of the outlet air flow velocity on the angular velocity of the working body: 1,3 - experimental data; 2.4 - calculated data.

working chamber processes showed that the air flow executes a complex rotational motion in the longitudinal and transverse directions (Figure 3a, b) and creates local areas of increased turbulence 1, Figure 3b. The mathematical modeling and an analysis of the results revealed that the air flows in the vicinity of the working body can be divided by their cross-sections into three groups: the flows in front of the working body, region 1, Figure 3a, which occur at a distance of $15-20 \mathrm{~mm}$ in front of the working body; the flows behind the working body, region 2 Figure $3 a$, which are observed at a distance of 60-70 $\mathrm{mm}$ behind the working body; and the relatively undisturbed flows, region 3, Figure 3a. The average material flow velocity in the vicinity of the beaters is $12.6 \mathrm{~m} / \mathrm{s}$ and the speed of the working body is $68.72 \mathrm{~m} / \mathrm{s}$. Thus, the relative velocity of the material flow collision with the beaters is $56 \mathrm{~m} / \mathrm{s}$, that is $81.5 \%$ of the rotational speed of the working body (Figure 3).

When passing through the clearances between the beaters, the air together with the material particles entrapped accelerates to $31 \mathrm{~m} / \mathrm{s}$; it forms turbulent cavities and concentrations of material in the vicitnity of the working body beaters, which is important from the point of view of improving the grinding efficiency.

In the material grinding, an important factor is the velocity of the material collisions with the working body; in this regard, the dependence of the collision velocity on the angular velocity of the working body was investigated. It has been established that the velocity of the air and solid particle flow collision with the working body beaters may be approximated by a linear function with a mean 
square deviation of 0.99 (Figure 4).

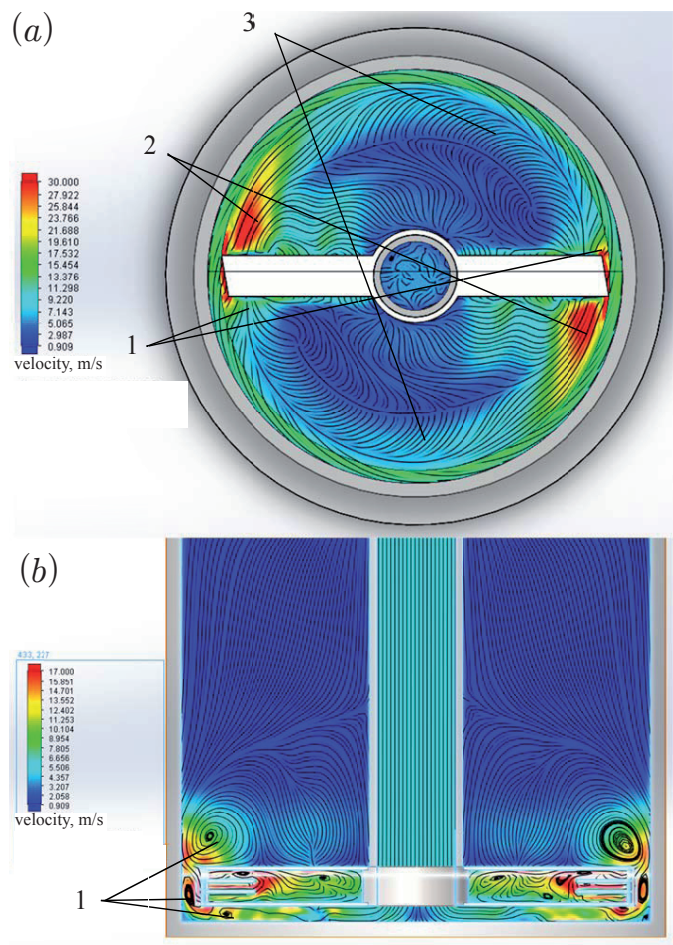

Fig. 3: Velocity fields and trajectories of air and solid particle flows at the working body angular velocity of $498 \mathrm{~s}^{-1}$ : a - longitudinal section, b-cross-section.

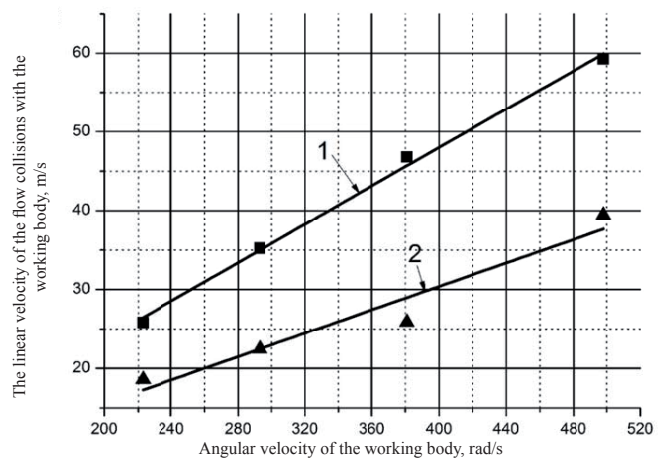

Fig. 4: Dependence of the linear velocity in the air flow collisions with the working body in the vicinity of the beaters: 1 - flows in region $3 ; 2$ - flows in region 1.

The throughput of the mill is determined by two factors: the rate of formation of the final class (grinding rate) and rate of the final class discharge from the grinding chamber. Therefore, an important scientific and practical result of the study has been estimating the dependence of the particle maximum sizes at the grinding chamber outlet on the flow velocity and rarefaction generated at the outlet.

The calculated diameters of the particles discharged from the grinding chamber by the flow at various flow rates are presented in Figure 5 .

The dependences of the maximum diameters dmax of the particles, discharged from the grinding chamber, on the outlet air flow rate were determined experimentally. The results obtained are summarized in Figure 6, which shows the dependence of dmax on the relative air flow rate evaluated as the ratio of the air flow rate to the volume of the grinding chamber $\mathrm{q}=\mathrm{Q} / \mathrm{V}(\mathrm{Q}$ is the air flow rate, $\mathrm{V}$ is the chamber volume).

Trajectories of motion of solid particles are determined by the integration of pseudo-time steps of the equation of balance of forces acting on a particle recorded in the Lagrangian reference frame:

$\frac{d u_{p}}{d t}=F_{D}\left(u-u_{p}\right)+\frac{g\left(\rho-\rho_{p}\right)}{\rho_{p}}$

where: $u$ - vector of the velocity of the gas medium, $\mathrm{m} / \mathrm{s} ; u_{p}$ - vector of the speed of solid particles $\mathrm{m} / \mathrm{s}$; $F_{D}=\frac{18 \mu C_{D} \mathrm{Re}}{\rho_{p} d_{p}^{2} 24}-$ force of the hydraulic resistance, referenced to the unit mass of the particle, $\mathrm{s}^{-1}$; $C_{D}$-dimensionless coefficient of hydraulic resistance; $\rho_{p}$ - density of solid particles $\mathrm{kg} / \mathrm{m}^{3} ; \operatorname{Re}=\frac{\rho d_{p}\left|u_{p}-u\right|}{\mu}$ - average diameter of solid particles, m; Reynolds number.

The developed technique was used to investigate the effect of pressure at the centrifugal mill outlet on the fineness of the discharged material (Figure 7)
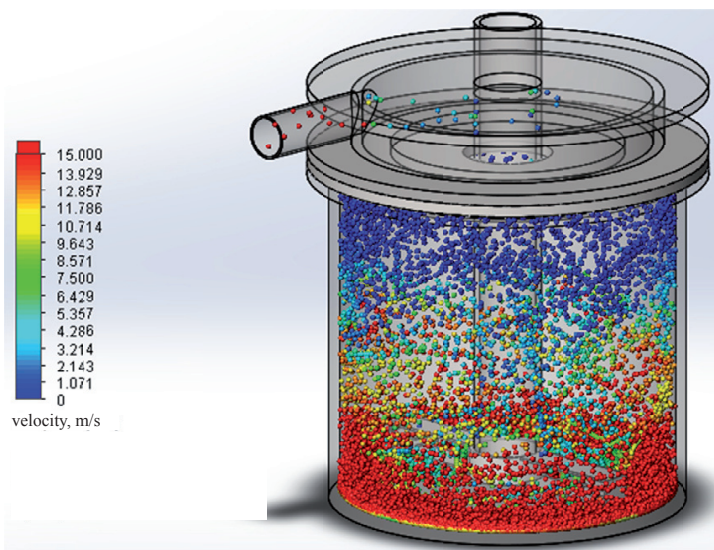

Fig. 5: Results of modeling the processes of classification and dis charge of the final class at an outlet flow velocity of $9 \mathrm{~m} / \mathrm{s}$. 


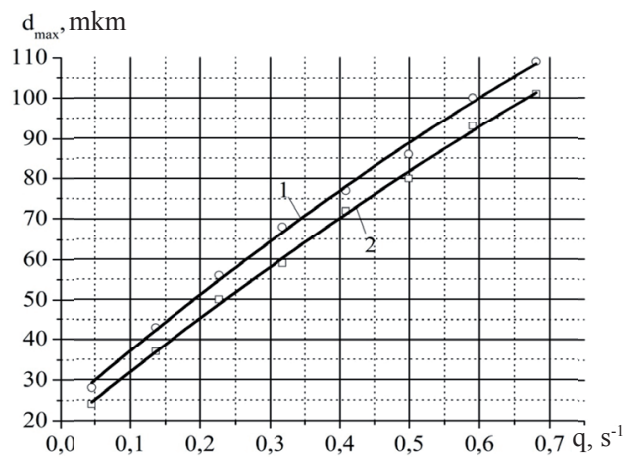

Fig. 6: Dependence of the maximum diameter of particles, discharged from the grinding chamber, on the relative air flow rate at the outlet: 1,2 - experimental and calculated dependences, respectively.

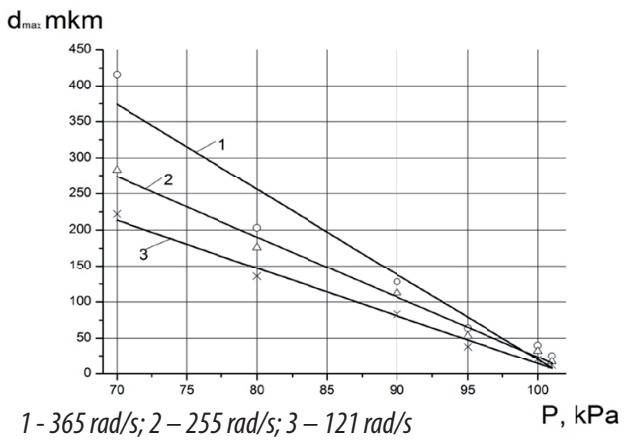

Fig. 7: Dependence of the maximum diameters of particles, discharged from the grinding chamber, on the outlet pressure.

1. A method to investigate the aeromechanical processes in the flow part of the centrifugal mill has been developed, which allows estimating the aeromechanical flows in the grinding chamber of the centrifugal mill, taking into account the design features of the flow part and working body, the parameters of the material to be ground and the pressures at the inlet and outlet. The method can also be applied to reveal the patterns of influence of the above factors on the discharging the maximum diameters of the material being ground. A comparison of the experimental and calculated data shows that the error does not exceed $15 \%$.

2. It has been established that the size of the ground material particles that are discharged from the centrifugal mill is proportional to the air flow rate and vacuum-gauge pressure at the discharge chamber outlet.

3. The linear and angular velocities of the collision of air and solid particle flows with the beaters are proportional to the angular velocity of the working body.

\section{Conclusions}

Based on the results of the study, regularities have been obtained that make it possible to design a centrifugal mill for a given productivity and granulometric composition.

\section{References and Notes}

[1] Pat. 90631 Ukraine, IPC B02C 13/14. Vidcentrovyj mlyn udarnoji diji [Centrifugal Impact Mill] / Vynoghradov B.V. Jemeljjanenko V.I. Ostashko I.O. (Ukraine); Applicant and patent holder "Ukr. State Chem - Tech. University", no.200905165; filed May 25, 2009; published May 11, 2010; Bull No. 9

[2] Vinogradov, B.V. (2009) Izmelchenie tverdykh ostatkov protsessa piroliza iznoshennykh avtomobilnykh shin $v$ tsentrobezhnoy melnitse [Grinding of solid residues of the pyrolysis process of worn-out automobile tires in a centrifugal mill] / B.V. Vinogradov, I.A. Ostashko, V.I. Yemelyanenko // Voprosy khimii i khimicheskoy tekhnologii [Problems of Chemistry and Chemical Technology], no. 2, 2009, pp. 159161

[3] Vinogradov B.V., Ostashko I.A. (2009) Ob energeticheskikh kharakteristikakh tsentrobezhnykh melnits s S-obraznym rabochim organom [On the energy characteristics of centrifugal mills with an S-shaped working body] // Vistnyk NTU «KhPI», no. 25, pp. 164-169.

[4] Vynoghradov, B.V (2012) Doslidzhennja robochogho orghanu vidcentrovogho mlyna [Investigation of the working body of the centrifugal mill] / B.V. Vinogradov, I.A. Ostashko // Voprosy khimii i khimicheskoy tekhnologii (Problems of Chemistry and Chemical Technology), no. 5, pp. 182-184.

[5] Nikitin Ye.G., Galerkin Yu.B., Kozhukhov Yu.V. (2010) Metodika postroeniya raschetnoy setki oseradialnogo rabochego kolesa tsentrobezhnogo kompressora dlya rascheta vyazkogo techeniya s ispolzovaniem paketa programm ANSYS CFX [Method of constructing a computation mesh of an oscillating impeller of a centrifugal compressor for calculating a viscous flow using the ANSYS CFX program package]. Proceedings of the XXXIX Nedelya nauki SPbGPU international scientific-practical conference, part. III, pp. 91-93. Manuscript mailing instructions

\section{Biographical notes}

Ostashko Ihor Oleksandrovych: an engineer at the Department of Chemical Production Equipment at the Ukrainian State University of Chemical Technology. He graduated from this university in 2008 with a master's degree in the automation of production processes. His research is related with improvements of raw-material grinding equipment. Over the past five years, he has published more than 10 scientific articles, among them: Vinogradov B., Ostashko I. Substantiation of key parameters of a centrifugal mill intended for grinding solid residue from the pyrolysis of used automobile tyres. Scientific Journal of Silesian University 
Acta Mechanica Slovaca

Journal published by Faculty of Mechanical Engineering - Technical University of Košice

of Technology. Series Transport. 2016, 91, 133-141. ISSN: 0209-3324. DOI:

10.20858/sisutst.2016.91.14.

Prof. Vynohradov Borys Volodymyrovych: Doctor of Technical Sciences, Head of the Department of Chemical Production Equipment at the State Higher Educational Institution Ukrainian State University of Chemical Technology.

In 1962 he graduated from the Dnepropetrovsk Mining Institute with a degree in the specialty of "Mining Machines"; In 1983 he graduated from the doctorate and in 1985 he defended his doctoral dissertation in the field of "Mining Machines" on the theme "Theory and rationale of rational parameters of mechanical systems of drum mill drives." He received a doctorate in technical sciences and a professor's certificate (1986).

He Works in the field of development of theory and methods of calculating the mechanical systems and processes of production equipment. Prof. B.Vinogradov has made a significant contribution to the development of the theory and methods of calculating the mechanical systems of the drives of drum mills. He is a member of the scientific council of the Ministry of Education and Science of Ukraine in the professional direction "Mechanics." Over the past five years, he has published 14 scientific papers that are part of Scopus science-based database; his principal works are given below: Vinogradov B.V. Zhorstkist vidkritih zubchastih peredach barabannih mliniv / B.V. Vinogradov, D.A. Fedin // Naukovij visnik NGU, 2016, №. - C.24 - 30. Vinogradov B.V. Uprugie mufty s rezinokordnymi obolochkami v dvuzhdvigatel'nyh privodah barabannyh mel'nic / B.V.V Vinogradov, A.V. Hristenko // Naukovij visnik NGU, 2016, №1 - C. 42 - 47. Vinogradov B.V. Limitation of dynamic loads in machine drives [Text] / B.V. Vinogradov, J. Homišina, V. Khristenko // DIAGNOSTYKA, 2016, Vol. 17, No. 2 ISSN 1641-6414. Vinogradov B.V. and Fedin D.0., 2016 The stress state of heavy loaded open gearing with incomplete tooth contact, Scientific Bulletin of National Mining University, No.3 (153), pp.35 - 40. Vinogradov B.V. Naprjazhennoe sostojanie tjazhelonagruzhennyh otkrytyh zabchatyh peredach pri nepolnom kontakte zub'ev / B.V. Vinogradov, D.A. Fedin // Naukovij visnik NGU, 2016, №.3- C.35 $-40)$. 